\title{
Prevalence and severity of syndrome $Z$ in women with metabolic syndrome on waiting list for bariatric surgery: a cross-sectional study
}

Eduardo Araujo Perez ${ }^{1,2}$, Luis Vicente Franco Oliveira ${ }^{3,4^{*}}$, Wilson Rodrigues Freitas Jr. ${ }^{1}$, Carlos Alberto Malheiros ${ }^{1}$, Elias Jirjoss Ilias ${ }^{1}$, Anderson Soares Silva², Jessica Julioti Urbano², Patricia Clemente Oliveira ${ }^{2}$, Felipe X. Cepeda ${ }^{5}$, Luciana M. M. Sampaio ${ }^{2}$, Ivani C. Trombetta ${ }^{6}$, Humberto Delle ${ }^{6}$, Daniel Gianella Neto ${ }^{6 \wedge}$, Sergio Roberto Nacif ${ }^{7}$ and Roberto Stirbulov ${ }^{1}$

\begin{abstract}
Background: In recent years, obesity has become one of the most important public health problems in the world, with a growing prevalence in both developed and developing countries. Recent studies show that sleep disturbances, especially obstructive sleep apnoea (OSA) may be a manifestation of metabolic syndrome (MetS). Although the association of OSA with the MetS is largely attributed to obesity, the exact pathophysiological mechanisms and their individual characteristics still need to be identified. This study investigated the prevalence and severity of syndrome $Z$ in obese women with MetS on waiting list for bariatric surgery.
\end{abstract}

Methods: In this double-center cross-sectional study, female patients aged $\geq 18$ years, stage III severe obesity with MetS, on waiting list for bariatric surgery were recruited. The diagnosis for MetS was made according to the criteria of the national cholesterol education program, adult treatment panel III. Clinical, anthropometric, demographic, biochemistry, and sleep measurements were collected. Correlations between continuous variables with sleep parameters were performed using the Pearson correlation test or Spearman correlation test.

Results: The mean age of 83 patients was $44.8 \pm 11.2$ years and mean BMI was $42.6 \pm 8.1 \mathrm{~kg} / \mathrm{m}^{2}$. There was a significant correlation between OSA and metabolic score $(r=0.336 ; P=0.002)$, neck circumference $(r=0.218 ; P=0.048)$, basal systolic blood pressure $(r=0.280 ; P=0.01)$, total cholesterol $(r=0.277 ; P=0.011)$ and abdomen circumference $(r=0.284 ; P=0.009)$. The mean values of excessive daytime sleepiness were $10.5 \pm 7$ demonstrating a value considered normal for its presence. However, a high risk for OSA was observed in practically the entire population. It was observed that the prevalence of Syndrome Z (75.9\%) increased significantly according to apnoea hypopnoea index (AHI) (P for trend $<0.0000$ ). A prevalence of $27.71 \%$ for mild OSA, 20.48\% for moderate OSA, and $27.71 \%$ for severe OSA was observed. An association of AHI severity with all components of MetS was also observed.

Conclusions: We can conclude that syndrome Z presents a high prevalence in a female population with MetS and a considerable severity according to the presence of OSA. Therefore, patients with MetS should be investigated for the presence of sleep disorders.

Trial registration The study has been registered on ClinicalTrials.gov NCT02409160 and followed the standards of The Strengthening the Reporting of Observational Studies in Epidemiology (STROBE) Statement: guidelines for reporting observational studies

\footnotetext{
*Correspondence: oliveira.lvf@pq.cnpq.br

$\wedge$ Deceased

${ }^{4}$ Rua Itapicuru 380, Apto 111, Perdizes, Sao Paulo, SP CEP 05006-000,

Brazil

Full list of author information is available at the end of the article
} 
Keywords: Metabolic syndrome X, Obstructive sleep apnoea, Severe obesity, Polysomnography

\section{Background}

In recent years, obesity has become one of the most important public health problems in the world, with a growing prevalence in both developed and developing countries. This epidemic can be attributed to the modern lifestyle characterized by lack of physical activity and consumption of diets rich in fat $[1,2]$.

The obesity epidemic results in important health consequences for different ethnic populations. The increase in the number of obese people is associated with increases in the prevalence of comorbidities such as type 2 diabetes, hyperlipidemia, hypertension, obstructive sleep apnea (OSA), heart disease, stroke, asthma, weight bearing degenerative problems in the lower back and extremities, cancer and depression [3-5]. The importance of obesity in the development of cardiometabolic disease is highlighted every day [6].

Since metabolic syndrome (MetS) is strongly linked to obesity, the continuing rise in the prevalence of obesity worldwide is closely followed by increased rates of MetS. The national cholesterol education program (NCEP) adult treatment panel III (ATP III) introduced the term MetS in 2001, as a risk partner to elevated low-density lipoprotein (LDL) cholesterol in cholesterol guidelines [7, 8].

The term MetS is defined by a constellation of risk factors that usually accompany obesity and are associated with a higher risk for atherosclerotic cardiovascular disease (CVD) and type 2 diabetes $[9,10]$.

The MetS is a disorder characterized by abdominal obesity, arterial hypertension, increased blood triglycerides, decreased high-density lipoprotein (HDL) cholesterol and increased blood glucose $[11,12]$. Accumulating evidence indicates that insulin resistance and an increased amount of abdominal fat may be the pathogenic factors responsible for the variety of symptoms of the metabolic syndrome [13-15].

Recent studies show that sleep disturbances, especially OSA may be a manifestation of MetS [16, 17]. These observational studies have shown that OSA and MetS exhibit similar pathophysiological substrates for CVD, where increased blood pressure is a common consequence of these two pathologies. This raises another discussion whether MetS and OSA may have an additive effect on cardiovascular risk factors.

OSA is characterized by recurrent partial or complete collapse of the upper airway in the presence of ventilatory effort during sleep [18]. These events are often associated with recurrent nocturnal oxyhemoglobin desaturation, fragmented sleep, major fluctuations in blood pressure, and increased sympathetic nervous system activity and micro-arousal during sleep [19].

Several risk factors have been identified that contribute to the presence of respiratory sleep disorders (RSD) which include anatomical, mechanical and tissue changes of the upper airway, altered neuromuscular function and instability of the ventilatory control during sleep, and these factors predominate in individual cases, generating different "phenotypes" of OSA [20].

The main risk factors associated with OSA are age, male gender, body mass index (BMI), neck circumference, and craniofacial changes [21]. There is a clear relationship between OSA and cardiovascular risk, neuropsychological problems, reduction in quality of life and consequent increased use of health resources [22-24].

On the prevalence of OSA, three large cohort studies conducted in the United States of America: the Wisconsin sleep cohort study [25], the sleep heart health study [26] and the Penn State cohort [27] observed the presence of estimated sleep disturbances between 6.5 and $9 \%$ in women and between 17 and 31\% in men according to an apnea-hypopnea index (AHI) of more than five events per hour $[25,27]$.

A recent survey conducted with a representative population of the city of Sao Paulo showed that $24.8 \%$ of men and $9.6 \%$ of women presented OSA [28]. A recent study observed a prevalence of about $34 \%$ in men aged $30-70$ years and $17 \%$ in women aged $30-70$ years [29].

The HypnoLaus, a population-based study conducted in Lausanne, Switzerland is the lastest study on the prevalence of sleep-disordered breathing in the general population. The authors invited a cohort of 3043 consecutive participants from the CoLaus/PsyCoLaus study to take part. Polysomnography data from 2121 people were included in the final analysis. The median AHI was 6.9 events per hour (IQR 2.7-14.1) in women and 14.9 per $h$ (7.2-27.1) in men. The prevalence of moderate-to-severe sleep-disordered breathing ( $\geq 15$ events per $h$ ) was $23.4 \%$ (95\% CI 20.9-26.0) in women and $49.7 \%(46.6-52.8)$ in men [30].

There is already considerable scientific evidence based on human and animal studies suggesting that OSA can influence all aspects of MetS, including obesity [31], insulin resistance [32], and dyslipidemia [33, 34]. Other studies have also shown the coexistence of these two pathologies [35, 36]. It has been suggested that the metabolic syndrome "syndrome X" may include OSA and must then be called "syndrome Z" [37]. 
Although the association of OSA with the metabolic syndrome is largely attributed to obesity, the exact pathophysiological mechanisms and their individual characteristics still need to be identified. This study was performed to investigate the prevalence and severity of syndrome $\mathrm{Z}$ in obese women with metabolic syndrome on waiting list for bariatric surgery.

\section{Methods}

\section{Subjects and recruitment}

In this double-center cross-sectional study, women patients with metabolic syndrome on the waiting list for bariatric surgery undergoing polysomnography (PSG) in the sleep laboratory of the Nove de Julho university (UNINOVE), Sao Paulo (SP), Brazil, between June 2015 and September 2016 were evaluated for enrollment. These patients were referred for PSG from the surgery unit of the Hospital of Santa Casa de Misericordia and Hypertension Unit of Hospital das Clinicas da Faculdade de Medicina da Universidade de Sao Paulo (HCFMUSP) from the city of Sao Paulo (SP), Brazil. Participants were recruited consecutively, according to the eligibility criteria of the research protocol.

\section{Eligibility criteria}

Were recruited female patients, aged $\geq 18$ years, with stage III severe obesity (BMI of $\geq 40$ or $\geq 35 \mathrm{~kg} / \mathrm{m}^{2}$ with comorbidities) on the waiting list for bariatric surgery, diagnosed with MetS according to the criteria of the national cholesterol education program, adult treatment panel III (NCEP ATP III) [8], with a documented history of failed conventional weight loss attempts, and the ability to understand and agree to participate in the study, based on a signed informed consent. The MetS was defined as the presence of three or more of the following criteria: waist circumference $>88 \mathrm{~cm}$, fasting glucose $\geq 100 \mathrm{mg} / \mathrm{dl}$ or treatment with oral agents, triglycerides $\geq 150 \mathrm{mg} / \mathrm{dl}$ or treatment for it, HDL cholesterol $<50 \mathrm{mg} / \mathrm{dl}$ or lipid-lowering treatment, blood pressure $\geq 130 / 85 \mathrm{mmHg}$ or taking antihypertensive $[7,8]$. The exclusion criteria will be BMI of $>55 \mathrm{~kg} / \mathrm{m}^{2}$, alcohol or drug abuse, cancer, and any other cardiorespiratory and/ or neurological disorders.

\section{Ethics and trial registration}

Informed consent was obtained from all patients prior to entry into the study. All patients were given an information sheet detailing the purpose of the study and the study procedure. This study was conducted according the principles of the Declaration of Helsinki, and approved by the human research ethics committees of Nove de Julho university (UNINOVE; Protocol Number 220506/2009) and Irmandade da Santa Casa de Misericordia de Sao Paulo,
Brazil (Protocol Number 742.865/2014), and registered at ClinicalTrials.gov (NCT02409160). This protocol followed the STrengthening the Reporting of OBservational studies in Epidemiology (STROBE) [38] and the study has been registered on ClinicalTrials.gov NCT02409160. The Fig. 1 show the flow diagram of the study.

\section{Clinical, anthropometric and demographic measurements} Clinical, anthropometric and demographic measurements were collected in all included patients: medical history, medication use, blood pressure in sitting position (three measurements), BMI $\left(\mathrm{kg} / \mathrm{m}^{2}\right)[39,40]$, neck circumference (at laryngeal prominence) [41] and waist circumference (measured at the last rib and the iliac crest) [42].

\section{Laboratory measurements}

After fasting overnight, venous blood samples were obtained. Glycose, total cholesterol (TC), HDL cholesterol, LDL cholesterol and triglycerides were measured. Fasting cholesterol, triglyceride (Bayer Corporation, Tarrytown, NY, USA), and HDL cholesterol (Sigma Diagnostics, St. Louis, MO, USA) concentrations were measured using an immune colourimetric assay on an ADVIA $^{\circledR}$ 1650 chemistry system (Bayer Corporation, Tarrytown, NY, USA). LDL cholesterol were derived using the Fried Wald equation. Fasting glucose were measured using a glucose-oxidase-based assay (YSI 2300, Analytical Technologies, Farnborough, UK).

\section{Sleep assessment}

All patients underwent PSG within a maximum period of 15 days after blood collection. Sleep studies were carried out at the Nove de Julho University's sleep laboratory, by trained technicians using the system with 16-channel PSG Somnologica Studio-Embla A10 version 3.1.2 (Flaga Hs.Medical Devices, Reykjavik, Iceland), recording electroencephalography (EEG) (C4A1, C3A2, O2A1, O1A2), bilateral electrooculography (EOG), submental and bilateral tibialis anterior electromyography (EMG), electrocardiography (EKG), oxygen saturation, body position, thoracic and abdominal movements, oronasal flow by thermistor, nasal flow by cannula and snoring. All exams were read and scored manually blinded to clinical data by certified physicians experienced in sleep medicine according to the criteria of the American Academy of Sleep Medicine (AASM) manual for sleep scoring version-2 which was published in 2012 [18].

Apnoea and hypopnoea were defined according to the criteria as recommended by the AASM. Apnea was defined as the absence or reduction of over $90 \%$ of the respiratory signal with duration of at least $10 \mathrm{~s}$. The hypopnea was defined as an airflow reduction between 


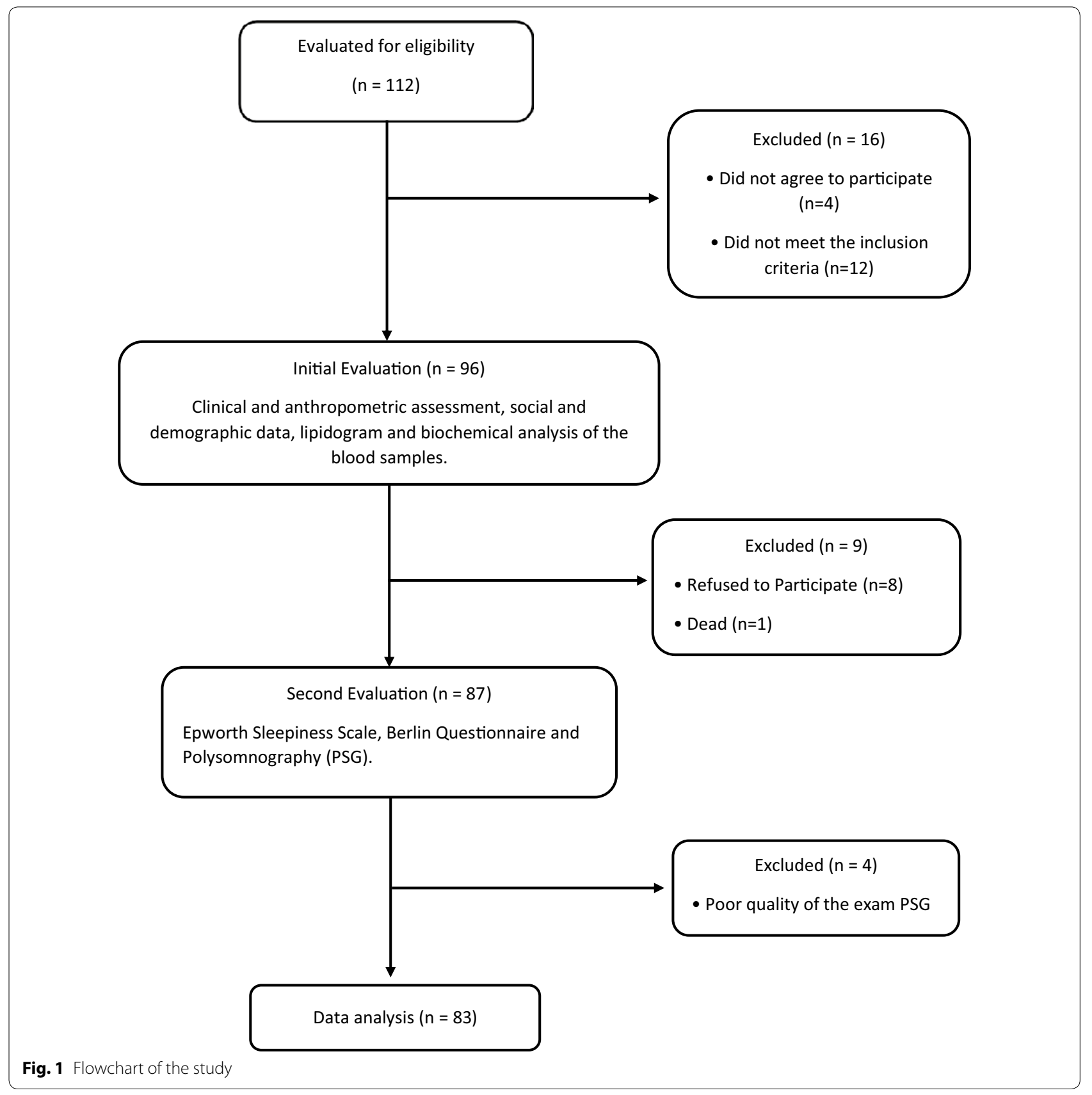

30 and $90 \%$ with a minimum of $10 \mathrm{~s}$ accompanied by an oxygen desaturation more than $4 \%$ and/or arousals. Were defined sleep fragmentation based on the number of awakenings per hour. Oxygen desaturations were measured as the percentage of recording time with oxygen saturation below $90 \%(\mathrm{~T}<90)$.

The severity of OSA was defined as AHI $>5$ events $/ \mathrm{h}$. The AHI was calculated by dividing the total number of respiratory events by the total number of hours of sleep. Severity of OSA was graded as, mild OSA: AHI $\geq 5$ and
$<15$ events/h, moderate OSA: AHI $\geq 15$ and $<30$ events/h, and severe OSA: AHI $\geq 30$ events/h. Patients without OSA were referred to as normal [18].

\section{Statistical analysis}

The data with normal distribution are represented in mean and standard deviation, and the data with abnormal distribution are represented in median and interquartile range. The categorical data are in absolute numbers and the percentage of the total. First, the 
Kolmogorov-Smirnov normality test was performed. The values of pre- and post- bronchodilator spirometry were compared using the student's test. Correlations between continuous variables with PSG parameters were performed using the Pearson correlation test or Spearman correlation test. The Statistical Package for Social Sciences SPSS $19.0^{\circledR}$ (Chicago, IL, USA) was used for the statistical treatment. Statistical significance was set at $5 \%$ for all tests $(\mathrm{P}<0.05)$.

\section{Results}

From an initial sample of 142 eligible patients, 112 female patients were recruited during routine medical appointments at the Bariatric Surgery Outpatient Clinic of Santa Casa de Misericordia in Sao Paulo and at the Heart Institute (InCor), University of Sao Paulo's Clinics Hospital (SP), Brazil with clinical diagnosis of severe obesity with MetS, on the waiting list for bariatric surgery. According to the inclusion and exclusion criteria, some patients were excluded as shown in the study flow diagram (Fig. 1). The final analysis of the data counted on 83 patients.

The clinical, demographic, anthropometric and major comorbidities of the eighty-three patients involved in the study are presented in Table 1 . The mean age was $44.8 \pm 11.2$ years and mean BMI was $42.6 \pm 8.1 \mathrm{~kg} / \mathrm{m}^{2}$. There was no significant difference between the variables age, weight, BMI, tobacco and alcohol consumption showing homogeneity of the sample. However, when comparing waist and neck circumference values, a significant difference was observed when grouped according to the severity of OSA. Regarding ethnicity, we observed the predominance of Caucasoid. Previous treatment, 46 (55.4\%) patients taking antihypertensive drugs, 27 (32.5\%) patients receiving oral antidiabetic agents and 10 (12\%) patients taking hypolipemiant drugs.

Table 2 shows the clinical variables related to peripheral blood pressure and blood biochemical analysis of patients stratified according to the presence of OSA or not and according to their severity levels. Significant difference was observed regarding systolic blood pressure (SBP) between the mild, moderate and severe groups in relation to the group of patients who did not present OSA. Regarding glycose levels, a significant difference was observed comparing the moderate and severe groups with the non-OSA group. The other variables not presented statistical significance.

The PSG variables are shown in Table 3 according to the presence and severity of OSA. In relation to the total sleep time and sleep efficiency, no significant difference was observed. This shows that all patients slept well exceeding $85.5 \%$ of total record time. However, in relation to AHI, obstructive apnea index, central apnea index, mixed apnea index and hypopnea indices, a significant difference was observed when the groups were compared by severity. Also, the values referring to oxygen saturation and maximal heart rate (HR) presented significant differences.

Our sample was composed of severe obese women with MetS. In Fig. 2 we can observe that the prevalence of "Z" Syndrome (75.8\%) increased significantly according to AHI ( $\mathrm{P}$ for trend $<0.0000$ ). We can also observe that according to AHI criteria, 20 subjects had no OSA (24.1\%), 23 had mild OSA (27.7\%), 17 had moderate OSA (20.4\%), and 23 had severe OSA (27.7\%).

Figure 3 shows the prevalence of the each of the components of the MetS according to the absence and severity of OSA. It can be observed a higher prevalence of all components of MetS in patients with OSA, however, only

Table 1 Demographic and anthropometric characteristics of apneic and non-apneic patients

\begin{tabular}{|c|c|c|c|c|c|c|}
\hline Variables & $\begin{array}{l}\text { All patients } \\
(n=83)\end{array}$ & $\begin{array}{l}\text { No-OSA } \\
(n=20)\end{array}$ & $\begin{array}{l}\text { Mild OSA } \\
(n=23)\end{array}$ & $\begin{array}{l}\text { Moderate OSA } \\
(n=17)\end{array}$ & $\begin{array}{l}\text { Severe OSA } \\
(n=23)\end{array}$ & $\mathbf{P}$ \\
\hline Age & $44.8 \pm 11.2$ & $49.5 \pm 10.5$ & $48.7 \pm 12$ & $46.5 \pm 10.6$ & $48.8 \pm 13.6$ & \\
\hline Weight (kg) & $108 \pm 19$ & $104.9 \pm 21.1$ & $108.1 \pm 14.9$ & $103.8 \pm 16$ & $112.3 \pm 22.6$ & \\
\hline BMI $\left(\mathrm{kg} / \mathrm{cm}^{2}\right)$ & $42.6 \pm 8.1$ & $40.1 \pm 8$ & $41.2 \pm 6.6$ & $40.3 \pm 6$ & $41.9 \pm 8.2$ & \\
\hline Waist (cm) & $119.4 \pm 14.1$ & $111.6 \pm 13.1$ & $119.7 \pm 11.1$ & $126.7 \pm 14.8^{a}$ & $129.4 \pm 10.8^{a, b}$ & $* * *$ \\
\hline $\operatorname{Neck}(\mathrm{cm})$ & $40.3 \pm 3.4$ & $38.9 \pm 2.8$ & $40.9 \pm 3.6$ & $41.7 \pm 3.2^{a}$ & $43.3 \pm 2.5^{a, b}$ & $* * *$ \\
\hline \multicolumn{7}{|l|}{ Ethnicity } \\
\hline Caucasoid (\%) & 65.3 & 70 & 16.8 & 14.4 & 14.4 & \\
\hline Negroid (\%) & 34.6 & 7.2 & 10.8 & 6.0 & 13.2 & \\
\hline
\end{tabular}

OSA obstructive sleep apnea, $B M I$ body mass index, $K g$ kilogram, $\mathrm{cm}^{2}$ square centimeters, $S D$ standard deviation

*** $\mathrm{P}<0.001$; data are expressed as mean $( \pm S D)$ and percentage $(\%)$

a no-OSA vs moderate OSA or severe OSA

b mild OSA vs severe OSA 
Table 2 Clinical and metabolic variables of the apneic and non-apneic patients

\begin{tabular}{|c|c|c|c|c|c|c|}
\hline Variables & $\begin{array}{l}\text { All patients } \\
(n=83)\end{array}$ & $\begin{array}{l}\text { NO-OSA } \\
(n=20)\end{array}$ & $\begin{array}{l}\text { Mild OSA } \\
(n=23)\end{array}$ & $\begin{array}{l}\text { Moderate OSA } \\
(n=17)\end{array}$ & $\begin{array}{l}\text { Severe OSA } \\
(n=23)\end{array}$ & $\mathbf{P}$ \\
\hline $\mathrm{SBP}(\mathrm{mmHg})$ & $137.6 \pm 11.6$ & $126.2 \pm 7.4$ & $136 \pm 11.6^{\mathrm{a}}$ & $139.1 \pm 8.3^{a}$ & $148.1 \pm 5.4^{a, b, c}$ & $* * *$ \\
\hline $\mathrm{DBP}(\mathrm{mmHg})$ & $86.0 \pm 5.3$ & $84.5 \pm 7$ & $85 \pm 3.9$ & $85.9 \pm 5.3$ & $88.5 \pm 4$ & \\
\hline Glycose (mg/dl) & $124.3 \pm 34.3$ & $99.8 \pm 14.5$ & $117.6 \pm 22.6$ & $139.7 \pm 41.6^{a}$ & $142.3 \pm 36.5^{\mathrm{a}}$ & $* * *$ \\
\hline $\mathrm{TC}(\mathrm{mg} / \mathrm{l})$ & $237.2 \pm 30.2$ & $183.7 \pm 118.1$ & $198.3 \pm 36.8$ & $186.2 \pm 30.5$ & $181.5 \pm 38.3$ & \\
\hline $\operatorname{Tg}(\mathrm{mg} / \mathrm{dl})$ & $187.6 \pm 64.9$ & $221.9 \pm 41.9$ & $244 \pm 25.7$ & $234.7 \pm 25.5$ & $245.6 \pm 20.1$ & \\
\hline $\mathrm{HDL}(\mathrm{mg} / \mathrm{dl})$ & $40.1 \pm 6.0$ & $42.3 \pm 7.5$ & $41.2 \pm 7.2$ & $39 \pm 6.6$ & $38 \pm 4.1$ & \\
\hline LDL (mg/dl) & $132.5 \pm 33.1$ & $140.6 \pm 30.6$ & $128 \pm 30.3$ & $124.8 \pm 31.6$ & $135.5 \pm 38.8$ & \\
\hline VLDL (mg/dl) & $312.5 \pm 17$ & $39.2 \pm 22.4$ & $26.6 \pm 12$ & $28.9 \pm 12.8$ & $31.1 \pm 17.4$ & \\
\hline
\end{tabular}

OSA obstructive sleep apnea, SBP systolic blood pressure, DBP diastolic blood pressure, $T C$ total cholesterol, $T g$ triglycerides; $H D L$ high density lipoprotein, $L D L$ low density lipoprotein, $V L D L$ very low density lipoprotein, $S D$ standard deviation

*** $P<0.001$; data are expressed as mean ( $\pm S D$ )

a no-OSA vs mild OSA, moderate OSA or severe OSA

b mild OSA vs severe OSA

c Moderate OSA vs severe OSA

Table 3 Polysomnographic variables

\begin{tabular}{|c|c|c|c|c|c|}
\hline Variables & $\begin{array}{l}\text { NO-OSA } \\
(n=20)\end{array}$ & $\begin{array}{l}\text { Mild OSA } \\
(n=23)\end{array}$ & $\begin{array}{l}\text { Moderate OSA } \\
(n=17)\end{array}$ & $\begin{array}{l}\text { Severe OSA } \\
(n=23)\end{array}$ & $\mathbf{P}$ \\
\hline TST (min) & $368.3 \pm 72.7$ & $348.1 \pm 41.1$ & $354.8 \pm 36.6$ & $355.5 \pm 60.8$ & \\
\hline SE (\%) & $90.7 \pm 5.6$ & $89.5 \pm 10$ & $87.2 \pm 6.9$ & $85.9 \pm 8.6$ & \\
\hline NREM1\% & $3.8 \pm 1.9$ & $9.6 \pm 16$ & $6.1 \pm 2.1$ & $7.1 \pm 2.5$ & \\
\hline NREM $2 \%$ & $56.5 \pm 7.2$ & $50.5 \pm 11.9$ & $52.6 \pm 12$ & $55.3 \pm 5.6$ & \\
\hline NREM3\% & $25.5 \pm 7.8$ & $25.8 \pm 9.6$ & $27.6 \pm 8.8$ & $25.7 \pm 6.4$ & \\
\hline REM\% & $14.1 \pm 7.3$ & $13.6 \pm 5.3$ & $11.3 \pm 6$ & $11.1 \pm 6.9$ & \\
\hline $\mathrm{AHI} / \mathrm{h}$ & $3.4 \pm 0.9$ & $9.9 \pm 3.3$ & $21.2 \pm 5.5^{a, b}$ & $52 \pm 14.5^{a, b, c}$ & $* * *$ \\
\hline $\mathrm{OAl} / \mathrm{h}$ & $5.5 \pm 4.6$ & $6.6 \pm 4.2$ & $30.6 \pm 30.4$ & $88 \pm 67.2^{a, b, c}$ & $* * *$ \\
\hline $\mathrm{CAl} / \mathrm{h}$ & $0.5 \pm 0.5$ & $1.7 \pm 1.3$ & $1.6 \pm 0.8$ & $3.4 \pm 3$ & $* * *$ \\
\hline $\mathrm{MAl} / \mathrm{h}$ & 0 & $1 \pm 0$ & $1 \pm 0$ & $4.8 \pm 4.1$ & $* * *$ \\
\hline Hypop/h & $2.4 \pm 0.6$ & $8.6 \pm 3.3$ & $16.1 \pm 5.9$ & $35.4 \pm 14.9^{a, b, c}$ & $* * *$ \\
\hline SpO2 vigília & $95.9 \pm 1.6$ & $94.5 \pm 1.3$ & $95 \pm 1.6^{\mathrm{a}}$ & $93.2 \pm 2.1^{a, b, c}$ & $*$ \\
\hline $\mathrm{SpO}_{2}$ sleep & $94.6 \pm 2.5$ & $93.6 \pm 1.9$ & $93.7 \pm 1.2$ & $89.5 \pm 4.3$ & $* * *$ \\
\hline $\mathrm{SpO}_{2}<90 \%$ TST (\%) & $0.4 \pm 0.2$ & $23.5 \pm 35$ & $22.5 \pm 38.4$ & $39.3 \pm 35.1$ & $* * *$ \\
\hline $\mathrm{SpO}_{2}<80 \%$ TST (\%) & 0 & $8.5 \pm 0.3$ & $9.8 \pm 3.1$ & $11.3 \pm 3.5$ & $* * *$ \\
\hline $\mathrm{SpO}_{2}<70 \% \mathrm{TST}(\%)$ & 0 & $2.8 \pm 1.9$ & $3.5 \pm 1.7$ & $4 \pm 2.1$ & $* * *$ \\
\hline $\mathrm{RH}$ wake & $87 \pm 7.4$ & $85 \pm 8.6$ & $88 \pm 10.5$ & $87.5 \pm 13.2$ & \\
\hline HR med. sleep & $81.6 \pm 7.5$ & $75.5 \pm 14.1$ & $73 \pm 8.8$ & $72.5 \pm 9.1$ & \\
\hline HR máx. sleep & $137.6 \pm 43.6$ & $125.4 \pm 22.6$ & $104.6 \pm 15.8^{\mathrm{a}}$ & $103.2 \pm 16.0^{a, b}$ & $* *$ \\
\hline HR min. sleep & $48.2 \pm 8.5$ & $53.1 \pm 14.1$ & $41.1 \pm 12.5$ & $46.8 \pm 6.8$ & \\
\hline ODI/h & $4.5 \pm 5$ & $6.9 \pm 4$ & $17.3 \pm 8.1$ & $50.1 \pm 24.2$ & \\
\hline
\end{tabular}

Data are expressed as mean ( \pm SD) or no (\%)

OSA obstructive sleep apnea, TST total sleep time, SE sleep efficiency, NREM1 sleep stage 1 without rapid eye movements, NREM2 sleep stage 2 without rapid eye movements, NREM3 stage 3 of sleep without rapid eye movements, REM sleep with rapid eye movement, $A H I$ apnea/hypopnea index per hour of sleep, OAI obstructive apnea index per hour of sleep, CAl central apnea index per hour of sleep, MAI mixed apnea index per hour of sleep, Hipop/h hypopnea index per hour of sleep, $\mathrm{SpO}$, peripheral oxyhemoglobin saturation, $H R$ heart rate, $O D I$ oxyhemoglobin desaturation index, Min minutes, $S D$ standard deviation

$* \mathrm{P}<0.05$;* $\mathrm{P}<0.01 ; * * \mathrm{P}<0.001$

a No-OSA vs moderate OSA or severe OSA

b Mild OSA vs moderate OSA or severe OSA

c Moderate OSA vs severe OSA 
a significant difference was observed regarding the values of SBP and glycose.

Table 4 shows a significant association between some components of MetS (HDL <40/50, fasting glycose $>100 \mathrm{mg} / \mathrm{dl}$, arterial hypertension, and triglycerides $>150 \mathrm{mg} / \mathrm{dl}$ ) and OSA.

When the correlation between the variables is analyzed, it is possible to verify that the OSA has significant correlation with metabolic score $(\mathrm{r}=0.336$; $\mathrm{P}=0.002)$, neck circumference $(r=0.218 ; \mathrm{P}=0.048)$, basal SBP $(\mathrm{r}=0.280 ; \mathrm{P}=0.01)$, TC $(\mathrm{r}=0.277 ; \mathrm{P}=0.011)$ and abdomen circumference $(\mathrm{r}=0.284 ; \mathrm{P}=0.009)$, according Fig. 4.

\section{Discussion}

Obesity is one of the major public health problems in developed and developing countries, causing a series of respiratory and metabolic changes. MetS is an association of metabolic and cardiovascular disorders including central obesity, insulin resistance, dyslipidemia and
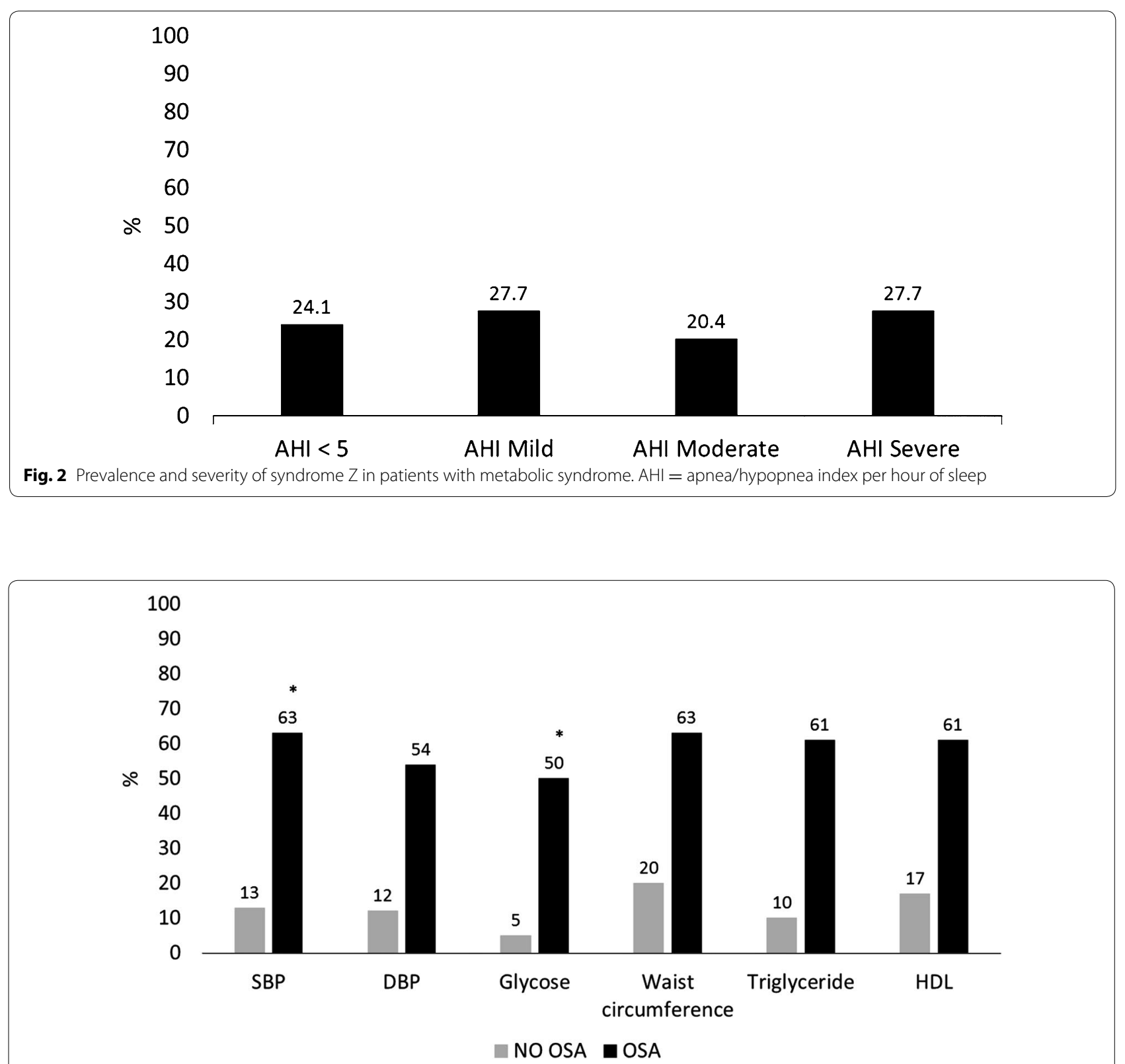

Fig. 3 Prevalence of metabolic syndrome components according absence and severity of obstructive sleep apnea. SBP = systolic blood pressure; $\mathrm{DBP}=$ diastolic blood pressure; $\mathrm{HDL}=$ high density lipoprotein; $\mathrm{OSA}=$ obstructive sleep apnea; $\mathrm{AHI}=$ apnea-hypopnea index. $\left({ }^{*} \mathrm{P}<0.05\right)$ 
Table 4 Association between metabolic syndrome components and presence or absence of obstructive sleep apnea

\begin{tabular}{|c|c|c|c|c|c|c|}
\hline \multirow[t]{2}{*}{ Variables } & \multirow{2}{*}{$\begin{array}{l}\mathrm{AHI}<5 \\
(n=20)\end{array}$} & \multirow{2}{*}{$\begin{array}{l}\mathrm{AHI} \geq 5 \\
(n=63)\end{array}$} & \multirow[b]{2}{*}{ OR } & \multicolumn{2}{|l|}{$95 \% \mathrm{Cl}$} & \multirow[b]{2}{*}{$P$ value } \\
\hline & & & & Lower & Upper & \\
\hline $\mathrm{HDL}<40 / 50$ & $16(80)$ & $62(98)$ & 15.5 & 1.6 & 148.4 & $* *$ \\
\hline Fasting glycose $>100 \mathrm{mg} / \mathrm{dl}$ & $9(45)$ & $55(87)$ & 8.4 & 2.6 & 26.5 & $* * *$ \\
\hline Arterial hypertension & $12(60)$ & $61(96)$ & 20.3 & 3.8 & 107.8 & $* * *$ \\
\hline Triglycerides > 150 mg/dl & $10(50)$ & $62(98)$ & 62.0 & 7.1 & 538.3 & $* * *$ \\
\hline
\end{tabular}

Number of subjects (\% in the group)

$A H I$ apnea-hypopnea index, $\mathrm{Cl}$ confidence interval, $\mathrm{OR}$ odds ratio, $H D L$ high-density lipoprotein-cholesterol

** $\mathrm{P}<0.01 ;{ }^{* * *} \mathrm{P}<0.001$
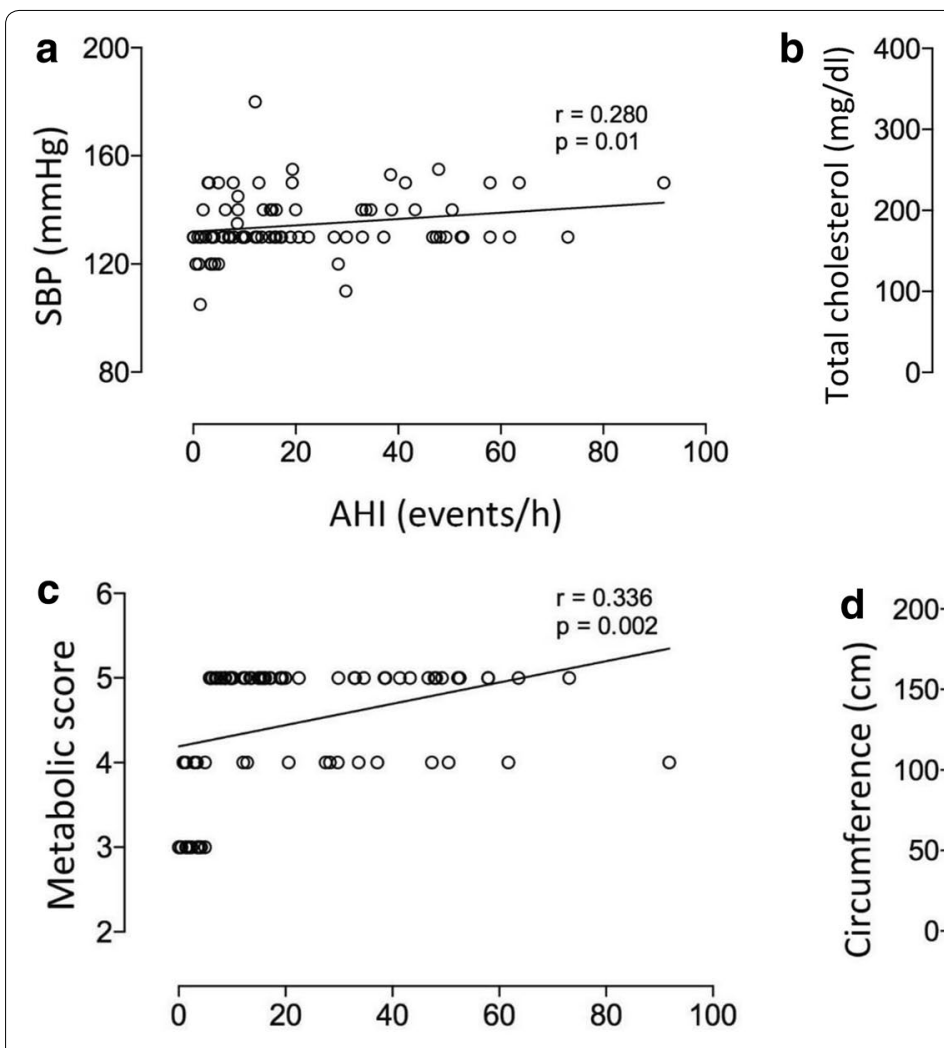

AHI (events/h)
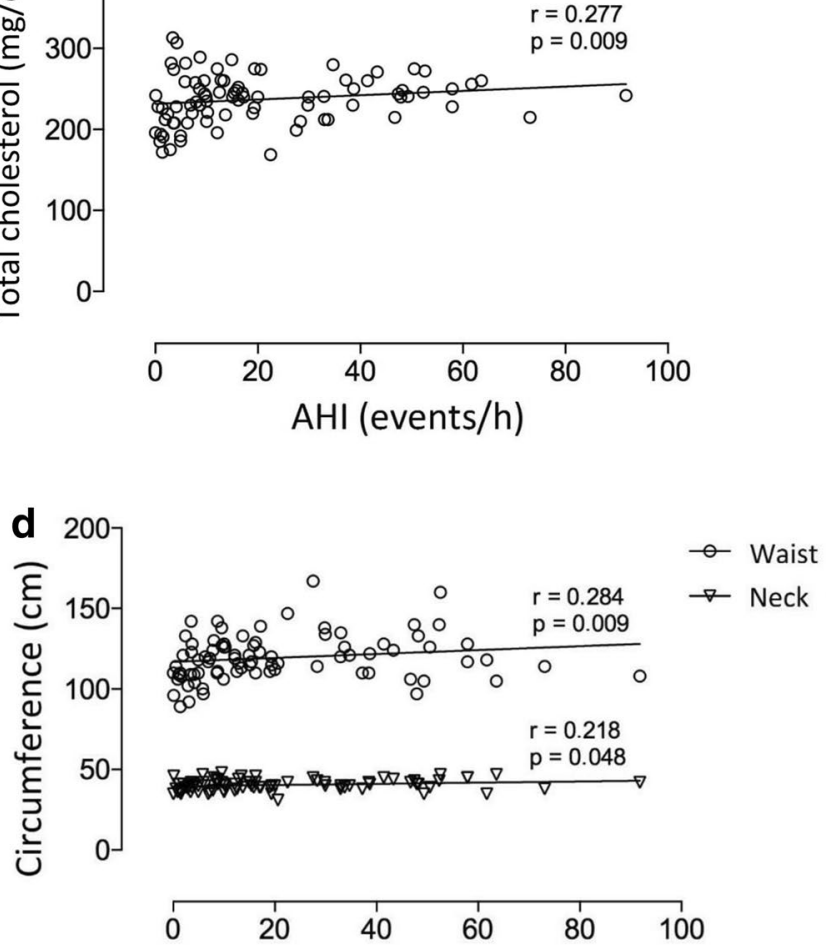

AHI (events/h)

Fig. 4 Correlation of apneia/hypopneia index and systolic blood pressure, cholesterol total, metabolic score and circumferences. SBP = systolic blood pressure; $\mathrm{AHI}=$ apneia/hypopneia index; $\mathrm{mmHg}=$ millimeters of mercury; $\mathrm{mg} / \mathrm{dl}=$ milligrams per deciliters; $\mathrm{cm}=$ centimeters; $\mathrm{h}=\mathrm{hour}$. $\mathrm{A}$ : correlation of SBP and $\mathrm{AH} ; \mathrm{B}$ : correlation of total cholesterol and $\mathrm{AH} ; \mathrm{C}$ : correlation of metabolic score and $\mathrm{AHI}$; $\mathrm{D}$ : correlation of circumference and $\mathrm{AHI}$

hypertension in the same patient. OSA is a common clinical condition present in patients with MetS. Recent studies have found that more than $60 \%$ of patients with MetS also have OSA and that they exhibit similar pathophysiological substrates for CVD, where increased blood pressure is a common consequence $[43,44]$.
This cross-sectional study characterized clinically a population of severely obese female patients on the waiting list for bariatric surgery and found a high prevalence of $\mathrm{Z}$ Syndrome. In addition to routine clinical exams, including blood biochemistry, PSG was also performed in all patients enrolled in the study. 
Regarding the demographic and clinical characteristics of the studied population, we can observe that there was no significant difference for the variables of age, weight and BMI, showing the homogeneity of the population even when stratified by groups according to the presence or absence of OSA and according with its gravity. However, it is worth mentioning the significant difference in hip and neck circumference measurements, presenting a considerable increase according to the AHI increase. Regarding the clinical and metabolic variables, a significant difference was observed only for the values of SBP and glycose among patients with and without OSA.

These findings are in agreement with the literature showing a considerable association of MetS with obesity, which are accompanied by increased risk of CVD and type 2 diabetes mellitus, highlighting dyslipidemia, hypertension and elevated glycose levels $[7,45]$.

For the physiological sleep variables, total sleep time, sleep efficiency and times in the different stages of sleep recorded during PSG, no significant difference was observed, showing that all the patients slept long enough for a good record, presenting an efficiency of normal sleep. However, for most of the variables related to sleep respiratory events, oxyhemoglobin saturation and maximum heart rate, a significant difference was observed. We would like to draw attention to the average saturation of oxyhemoglobin during wakefulness and during sleep and also to the percentage of sleep time below 80 and $70 \%$ of oxyhemoglobin saturation.

In the study of Venkateswaran and Shankar conducted in 2006 in a university hospital in Singapore involving 35 patients with MetS observed a prevalence of $62.5 \%$ of OSA verified by PSG [46]. In another study, in 2010 Agrawal et al. [47] observed a prevalence of $82 \%$ of Z Syndrome in a sample of 272 patients with MetS undergoing PSG. These authors also observed that the prevalence of MetS increases according to the severity of the proven OSA through AHI. In 2013, Barreiro et al. [48] found a prevalence of $82.2 \%$ of OSA and a significant association with the components of MetS in a sample of 141 patients with MetS in a hospital in Barcelona.

Our results corroborate these three studies, showing a prevalence of $75.8 \%$ of $Z$ Syndrome in patients with MetS and a tendency according to the severity of AHI. A prevalence of $27.7 \%$ for mild OSA, $20.4 \%$ for moderate OSA, and $27.7 \%$ for severe OSA was observed. An association of AHI severity with all components of MetS was also observed, but there was a significant difference only for SBP and for glucose levels.

Current scientific evidence suggests that OSA contributes independently to increased cardiometabolic risks, drawing the attention of healthcare professionals involved in the presence of metabolic dysfunction.
During the apneic event hypoxemia occurs associated with hypercapnia, with consequent stimulation of the sympathetic nervous system causing peripheral vasoconstriction. There is also a reduction in intrathoracic pressure and a decrease in pre and post cardiac load.

After restoration of the ventilatory flow, the circulating volume (preload) is increased during vasoconstriction, causing repetitive elevations of blood pressure during the night. Chronically, sustained elevations of blood pressure can be observed due to stimulation of sympathetic autonomic activity, reduction of parasympathetic activity, reduction of nitric oxide, and release of endothelin [49].

Hyperaldosteronism may be a cause of resistant hypertension in patients with OSA. Activation of the reninangiotensin system, inflammation, insulin resistance, decrease in baroceptor sensitivity, endothelial dysfunction, oxidative stress, and hyperleptinemia may also be implicated in the development of hypertension [31].

Another important finding of this study was the verification of the association between the components of the metabolic syndrome and the presence of OSA. Significant OR values were observed for HDL, fasting glycose, systemic arterial hypertension and hypertriglyceridemia. These data confirm the deleterious impact of OSA on the metabolic and inflammatory markers of the metabolic syndrome, proposed by Drager et al. [43].

In this study, the prevalence of excessive daytime sleepiness (EDS) was verified through the Epworth sleepiness scale $[50,51]$ and risk for OSA presence through the Berlin clinical questionnaire [52]. The mean values of SED were $10.5 \pm 7$ demonstrating a value considered normal for its presence. However, a low risk for OSA was observed in only one patient, although the prevalence of OSA was $75.9 \%$.

However, we believe that longitudinal population studies are needed to prove the causal relationship of OSA to metabolic disorders or otherwise, as well as controlled randomized multicenter studies to confirm the beneficial effect of positive airway pressure therapy on metabolic disorders In individuals with OSA.

\section{Conclusions}

According to the study, we can conclude that $\mathrm{Z}$ syndrome presents a high prevalence in a female population with MetS and a considerable severity according to the presence of OSA. Therefore, patients with MetS should be investigated for the presence of sleep disturbances and, if observed, referred for specific treatment.

\section{Abbreviations}

OSA: obstructive sleep apnoea; MetS: metabolic syndrome; NCEP ATP III: national cholesterol education program adult treatment panel III; LDL: 
low-density lipoprotein; CVD: cardiovascular disease; HDL: high-density lipoprotein; BMI: body mass index; AHI: apnea/hypopnea index per hour of sleep; PSG: polysomnography; TC: total cholesterol; EEG: electroencephalogram; EOG: electrooculogram; EMG: electromyogram; EKG: electrocardiogram; AASM: Americam Association of Sleep Medicine; SBP: systolic blood pressure; HR: heart rate; EDS: excessive daytime sleepiness.

\section{Authors' contributions}

RS, LVFO, DGN and EAP provided the concept of the study, created the hypothesis, and wrote the original proposal. EAP, WRFJ, RS, CAM, ASS, DGN and LVFO significantly contributed to the writing of this proposal. EAP, WRFJ, EJI, $J J U$ and PCO was involved in the clinical assessment of the patients. SRN, EAP, PCO, FXC, ICT, LMMS and ASS participated in the performance and reading of polysomnography exams. WRFJ, CAM, ASS, JJU, DGN, HD, SRN, RS, HD and LVFO were involved in the critical revision of the manuscript. EAP, LVFO, HD, DGN and RS wrote this paper, with input from all co-authors. All authors read and approved the final manuscript.

\section{Author details}

${ }^{1}$ Santa Casa School of Medicine, Sao Paulo, SP, Brazil. ${ }^{2}$ Sleep Laboratory, Nove de Julho University (UNINOVE), Sao Paulo, SP, Brazil. ${ }^{3}$ University Center of Anapolis (UniEVANGELICA), Anapolis, GO, Brazil. ${ }^{4}$ Rua Itapicuru 380, Apto 111, Perdizes, Sao Paulo, SP CEP 05006-000, Brazil. ${ }^{5}$ Heart Institute (InCor), Hospital das Clinicas da Faculdade de Medicina da, Universidade de Sao Paulo, Sao Paulo, SP, Brazil. ${ }^{6}$ Nove de Julho University (UNINOVE), Sao Paulo, SP, Brazil.

${ }^{7}$ Hospital Servidor Público Estadual (HSPE), Sao Paulo, SP, Brazil.

\section{Acknowledgements}

The authors want to thank to Lorenzi-Filho G, MD, Ph.D., for the logistical support and assistance with part of nocturnal polysomnography exams, evaluated in Sleep Laboratory, Pulmonary Division, Heart Institute (Incor), University of Sao Paulo Medical School, and the participants of the study.

We would like to express special thanks to Prof. Dr. Daniel Giannella Neto for the opportunity, learning and participation in this study.

In memorian: Daniel Giannella Neto, m.d. 1951-2017.

\section{Competing interests}

The authors declare that they have no competing interests.

\section{Availability of data and materials}

The individual-level data analyzed remain the intellectual property of the Post-Graduate Program in Surgery Research at the medical school faculty of Santa Casa de Sao Paulo. The authors are licensed users of the data, and under the licensing agreement, they are not allowed to share or distribute the data. Researchers who wish to access this data may contact the authors for more information.

\section{Ethics approval and consent to participate}

All participants gave written informed consent prior to any study related procedure. The study was conformed to the Declaration of Helsinki and approved by the Research Ethics Committee of the Santa Casa de Misericórdia (Process Number 178/2012) and Research Ethics Committee of the Nove de Julho University (Process Number 370474/2010) and registered in ClinicalTrials. gov NCT02409160

\section{Funding}

This study was supported by grants from the National Council for Scientific and Technological Development (CNPq) and Fundação de Amparo a Pesquisa do Estado de São Paulo (FAPESP \#2011/17533-6), and, in part, by Fundação Zerbini. LVFO receive Research Productivity modality IB grants by Conselho Nacional de Desenvolvimento Cientifico e Tecnologico (local acronym CNPq; Process No. 313053/2014-6).

\section{Publisher's Note}

Springer Nature remains neutral with regard to jurisdictional claims in published maps and institutional affiliations.
Received: 29 May 2017 Accepted: 12 September 2017

Published online: 20 September 2017

\section{References}

1. CDC. State-specific prevalence of obesity among adults United States. MMWR Morb Mortal Wkly Rep. 2006;55:985-8.

2. Poirier P, Giles TD, Bray GA, Hong Y, Stern JS, Pi-Sunyer FX, et al. Obesity and cardiovascular disease - pathophysiology, evaluation, and effect of weight loss. Arterioscler Thromb Vasc Biol. 2006;26:968-76.

3. WHO. Obesity: preventing and managing the global epidemic. Report of a WHO Consultation. Geneva:World Health Organization; 2016.

4. Must A, Spadano J, Coakley EH, Field AE, Colditz G, Dietz WH. The disease burden associated with overweight and obesity. JAMA. 1999;282:1523-9.

5. Yanovski SZ. Overweight, obesity, and health risk: national task force on the prevention and treatment of obesity. Arch Intern Med. 2000;160:898-904.

6. Prospective Studies Collaboration. Body mass index and cause specific mortality in 900,000 adults: collaborative analyses of 57 prospective studies. Lancet. 2009;373:1083-96

7. Expert Panel on Detection. Evaluation, and treatment of high blood cholesterol in adults. executive summary of the third report of the national cholesterol education program (NCEP) expert panel on detection, evaluation, and treatment of high blood cholesterol in adults (adult treatment panel III). JAMA. 2001:285:2486-97.

8. National cholesterol education program (NCEP) expert panel on detection, evaluation, and treatment of high blood cholesterol in adults (adult treatment panel III). Third report of the national cholesterol education program (NCEP) expert panel on detection, evaluation, and treatment of high blood cholesterol in adults (adult treatment panel III) final report. Circulation. 2002;106:3143-421.

9. Grundy SM, Brewer HB Jr, Cleeman JI, Smith SC Jr, Lenfant C, National heart, lung, and blood institute, et al. Definition of metabolic syndrome: report of the national heart, lung, and blood institute/American heart association conference on scientific issues related to definition. Circulation. 2004;109:433-8.

10. Lorenzo C, Okoloise M, Williams K, Stern MP, Haffner SM, San Antonio heart study. The metabolic syndrome as predictor of type 2 diabetes: the San Antonio heart study. Diabetes Care. 2003;26:3153-9.

11. Reaven GM. Pathophysiology of insulin resistance in human disease. Physiol Rev. 1995;75:473-86.

12. De Fronzo RA, Ferrannini E. Insulin resistance. A multifaceted syndrome responsible for NIDDM, obesity, hypertension, dyslipidemia and atherosclerotic cardiovascular disease. Diabetes Care. 1991;14:173-94

13. Zavaroni I, Bonora E, Pagliara M, Dall'Aglio E, Luchetti L, Buonanno G, et al. Risk factors for coronary artery disease in healthy persons with hyperinsulinemia and normal glucose tolerance. N Engl J Med. 1989;320:702-6.

14. Ferrannini E, Haffner SM, Mitchell BD, Stern MP. Hyperinsulinaemia: the key feature of a cardiovascular and metabolic syndrome. Diabetologia. 1991;34:416-22.

15. Laakso M, Sarlund H, Mykkanen L. Insulin resistance is associated with lipid and lipoprotein abnormalities in subjects with varying degrees of glucose tolerance. Arteriosclerosis. 1990;10:223-31.

16. Vgontzas AN, Bixler EO, Chrousos GP. Sleep apnea is a manifestation of the metabolic syndrome. Sleep Med Rev. 2005;9:211-24.

17. Coughlin S, Calverley P, Wilding J. Sleep disordered breathing-a new component of syndrome x? Obes Rev. 2001;2:267-74.

18. Berry RB, Budhiraja R, Gottlieb DJ, Gozal D, Iber C, Kapur VK, Quan SF, et al. Rules for scoring respiratory events in sleep: update of the 2007 AASM manual for the scoring of sleep and associated events. J Clin Sleep Med. 2012;8(5):597-619.

19. White DP. Sleep-related breathing disorder: 2-pathophysiology of obstructive sleep apnoea. Thorax. 1995;50:797-804.

20. McNicholas W, Bonsignore MR. Sleep apnoea. European respiratory monograph 50. Sheffield, European respiratory society; 2010. 
21. McNicholas WT, Bonsigore MR. Sleep apnoea as an independent risk factor for cardiovascular disease: current evidence, basic mechanisms and research priorities. Eur Respir. 2007;29:156-78.

22. Young T, Peppard PE, Gottlieb DJ. Epidemiology of obstructive sleep apnea: a population health perspective. Am J Respir Crit Care Med. 2002;165:1217-39.

23. Baldwin CM, Ervin AM, Mays MZ, Robbins J, Shafazand S, Walsleben J, et al. Sleep disturbances, quality of life, and ethnicity: the sleep heart health study. J Clin Sleep Med. 2010;6:176-83.

24. Sharma H, Sharma SK, Kadhiravan T, Mehta M, Sreenivas V, Gulati V, et al. Pattern and correlates of neurocognitive dysfunction in Asian Indian adults with severe obstructive sleep apnoea. Indian J Med Res. 2010;132:409-14.

25. Young T, Palta M, Dempsey J, Skatrud J, Weber S, Badr S. The occurrence of sleep-disordered breathing among middle-aged adults. N Engl J Med. 1993;328:1230-5.

26. Quan SF, Howard BV, Iber C, Kiley JP, Nieto FJ, O'Connor GT, et al. The sleep heart health study: design, rationale, and methods. Sleep. 1997;20:1077-85.

27. Bixler EO, Vgontzas AN, Lin HM, Ten Have T, Rein J, Vela-Bueno A, et al. Prevalence of sleep-disordered breathing in women: effects of gender. Am J Respir Crit Care Med. 2001;163:608-13.

28. Tufik S, Silva RS, Taddei JA, Bittencourt LRA. Obstructive sleep apnea syndrome in the São Paulo epidemiologic sleep study. Sleep Med. 2010;11(5):441-6.

29. Peppard PE, Young T, Barnet JH, Palta M, Hagen EW, Hla KM. Increased prevalence of sleep-disordered breathing in adults. Am J Epidemiol. 2013;177:1006-14.

30. Heinzer R, Vat S, Marques-Vidal P, Marti-Soler H, Andries D, Tobback N, et al. Prevalence of sleep-disordered breathing in the general population: the HypnoLaus study. Lancet Respir Med. 2015;3(4):310-8.

31. Peppard PE, Young T, Palta M, Skatrud J. Prospective study of the association between sleep-disordered breathing and hypertension. N Engl J Med. 2000;342:1378-84.

32. Punjabi NM, Sorkin JD, Katzel LI, Goldberg AP, Schwartz AR, Smith PL, et al. Sleep-disordered breathing and insulin resistance in middle-aged and overweight men. Am J Respir Crit Care Med. 2002;165:677-82.

33. Li J, Thorne LN, Punjabi NM, Sun CK, Schwartz AR, Smith PL, et al. Intermittent hypoxia induces hyperlipidemia in lean mice. Circ Res. 2005;97:698-706.

34. Savransky V, Jun J, Li J, Nanayakkara A, Fonti S, Moser AB, et al. Dyslipidemia and atherosclerosis induced by chronic intermittent hypoxia are attenuated by deficiency of stearoyl coenzyme A desaturase. Circ Res. 2008;103:1173-80.

35. Coughlin SR, Mawdsley L, Mugarza JA, Calverley PM, Wilding JP. Obstructive sleep apnoea is independently associated with an increased prevalence of metabolic syndrome. Eur Heart J. 2004;25:735-41.

36. Stephen W, Littleton MD, Babak M. The pickwickian syndrome-obesity hipoventilation syndrome. Clin Chest Med. 2009;30:467-78.
37. Wilcox I, McNamara SG, Collins FL, Grunstein RR, Sullivan CE. "Syndrome $Z^{\prime \prime}$ : the interaction of sleep apnoea, vascular risk factors and heart disease. Thorax. 1998;53(Suppl 3):S25-8.

38. Von Elm E, Altman DG, Egger M, Pocock SJ, Gøtzsche PC, Vandenbroucke JP, STROBE initiative. The strengthening the reporting of observational studies in epidemiology (STROBE)statement: guidelines for reporting observational studies. J Clin Epidemiol. 2008;61(4):344-9.

39. World Health Organization. Measuring obesity: classification and distribution of anthropometric data. Copenhagen: World Health Organization; 1989.

40. Obesity and overweight. Fact sheet. World Health Organization. Updated June 2016. http://www.who.int/mediacentre/factsheets/fs311/en.

41. Hingorjo MR, Qureshi MA, Mehdi A. Neck circumference as a useful marker of obesity: a comparison with body mass index and waist circumference. J Pak Med Assoc. 2012;62(1):36-40.

42. Vallianou NG, Evangelopoulos AA, Bountziouka V, Vogiatzakis ED, Bonou MS, Barbetseas J, et al. Neck circumference is correlated with triglycerides and inversely related with $\mathrm{HDL}$ cholesterol beyond $\mathrm{BMI}$ and waist circumference. Diabetes Metab Res Rev. 2013;29:90-7.

43. Drager LF, Lopes HF, Maki-Nunes C, Trombetta IC, Toschi-Dias E, Alves MJ, et al. The impact of obstructive sleep apnea on metabolic and inflammatory markers in consecutive patients with metabolic syndrome. PLoS ONE. 2010;5(e12065):3.

44. Trombetta IC, Somers VK, Maki-Nunes C, Drager LF, Toschi-Dias E, Alves $\mathrm{MJ}$, et al. Consequences of comorbid sleep apnea in the metabolic syndrome implications for cardiovascular risk. Sleep. 2010;3:1193-9.

45. Grundy SM, Cleeman JI, Daniels SR, Donato KA, Robert H, Barry AE, et al. Diagnosis and management of the metabolic syndrome. An American heart association/national heart, lung, and blood institute scientific statement. Circulation. 2005;112:2735-52.

46. Venkateswaran S, Shankar P. The prevalence of syndrome Z (the interaction of obstructive sleep apnoea with the metabolic syndrome) in a teaching hospital in Singapore. Postgrad Med J. 2007:83:329-31.

47. Agrawal S, Sharma SK, Sreenivas V, Lakshmy R. Prevalence of metabolic syndrome in a north Indian hospital-based population with obstructive sleep apnoea. Indian J Med Res. 2011;134:639-44.

48. Barreiro B, Garcia L, Lozano L, Almagro P, Quintana S, Alsina M, et al. Obstructive sleep apnea and metabolic syndrome in Spanish population. Open Respir Med J. 2013;7:71-6.

49. Goodfriend TL, Calhoun DA. Resistant hypertension, obesity, sleep apnea, and aldosterone: theory and therapy. Hypertension. 2004;43:518-24.

50. Murray WJ. Reliability and factor analysis of Epworth sleepiness scale. Sleep. 1992;15:376-81.

51. Bertolazi AN, Fagondes SC, Hoff LS, Pedro VD, Menna-Barreto SS, Johns MW. Portuguese-language version of the Epworth sleepiness scale: validation for use in Brazil. J Bras Pneumol. 2009;35:877-83.

52. Netzer NC, Stoohs RA, Netzer CM, Clark K, Strohj KP. Using the Berlin Questionnaire to identify patients at risk for the sleep apnea syndrome. Ann Intern Med. 1999;131:485-91.

\section{Submit your next manuscript to BioMed Central and we will help you at every step:}

- We accept pre-submission inquiries

- Our selector tool helps you to find the most relevant journal

- We provide round the clock customer support

- Convenient online submission

- Thorough peer review

- Inclusion in PubMed and all major indexing services

- Maximum visibility for your research

Submit your manuscript at www.biomedcentral.com/submit 